\title{
Association between irritable bowel syndrome and asthma: a meta-analysis and systematic review
}

\author{
Farah Deshmukha, Anupama Vasudevan ${ }^{\mathrm{b}}$, Erika Mengalie ${ }^{\mathrm{c}}$
}

Bassett Medical Center and Columbia University College of Physicians and Surgeons, NY; University of Texas Southwestern Medical Center, Texas; Case Western Reserve University - MetroHealth Medical Center, Cleveland, Ohio, USA

Abstract

\section{Introduction}

Irritable bowel syndrome (IBS) is a common functional gastrointestinal (GI) disorder with a worldwide prevalence of

Departments of a Internal Medicine, Bassett Medical Center and Columbia University College of Physicians and Surgeons, NY (Farah

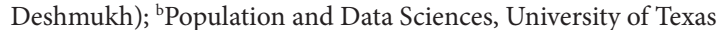
Southwestern Medical Center, Texas (Anupama Vasudevan); ' Internal Medicine, Case Western Reserve University - MetroHealth Medical Center, Cleveland, Ohio (Erika Mengalie), USA

\section{Conflict of Interest: None}

Correspondence to: Farah Deshmukh, MD, Department of Interna Medicine, Bassett Medical Center and Columbia University College of Physicians and Surgeons, New York, 1 Atwell Rd., Cooperstown, NY 13326, USA, e-mail: FarahDeshmukh@gmail.com

Received 20 July 2019; accepted 26 September 2019; published online 21 October 2019

DOI: https://doi.org/10.20524/aog.2019.0426
9-25\% [1,2]. It affects mainly young patients (below the age of 50 years) and is one of the most common reasons for patients to be seen in outpatient gastroenterology clinics [3-5]. In addition to decreased quality of life due to GI and extraintestinal manifestations, IBS has also been associated with a considerable healthcare cost burden and work-school absenteeism [2,6-9] The Rome criteria, the gold standard for diagnosing IBS, take into account the duration of GI symptoms and other factors such the association of symptoms with bowel movement and stool caliber or frequency $[1,3]$.

Asthma, another condition known to reduce patients' quality of life, is commonly associated with GI conditions such as gastroesophageal reflux disease and eosinophilic esophagitis $[10,11]$. The incidence of asthma with coexisting GI comorbidities has been rising worldwide [1]. The association between IBS and asthma was first identified in the 1990s; however, the question of how the 2 conditions are related is still unclear $[1,12]$. Patients with IBS and coexisting atopic disease have been shown to have higher immunoglobulin E levels and more likelihood of self-reported food intolerance. However, 
there have also been contradictory studies that showed no association between IBS and pulmonary conditions such as chronic bronchitis $[5,13,14]$. This systematic review and metaanalysis summarizes the available literature pertaining to the association of IBS and asthma in the adult population.

\section{Materials and methods}

A comprehensive literature review was completed using the MEDLINE and EMBASE databases through January 2019. All research studies that evaluated IBS and asthma in adults were reviewed. Published case-control, cross-sectional and cohort studies that evaluated the association between IBS and asthma were included. Pediatric and animal studies, editorials, letters and studies that did not provide information on the number of IBS or asthma patients were excluded. Based on the inclusion and exclusion criteria, a total of 10 studies were selected and analyzed for the meta-analysis.

The systematic review was conducted independently by 2 investigators (FD, EM), who independently screened the study titles and abstracts based on the inclusion and exclusion criteria. Key search terms included "irritable bowel syndrome", "functional bowel disorder", and "asthma". A more detailed list of search terms has been provided in the supplementary data. The study was conducted in accordance with the PRISMA (Preferred Reporting Items for Systematic reviews and MetaAnalyses) statement and study quality was assessed using the Newcastle-Ottawa scale (NOS).

\section{Statistical analysis}

Statistical analysis was performed using STATA Version 15 for Windows (StataCorp., Lake Station, TX, USA). A random effects meta-analysis was conducted, and heterogeneity was assessed using I-squared statistics to measure the variability across the studies included in the meta-analysis. The results were presented as odds ratios (OR) and a sensitivity analysis was conducted that included only the case control studies. A separate meta-analysis included studies that explored the risk of IBS in asthmatic patients and vice versa. Publication bias was assessed by funnel plot and the Harbord test for small-study effects.

\section{Results}

A total of 634 studies (186 from MEDLINE and 448 from EMBASE) were obtained using relevant search terms. One hundred fifty-three duplicate studies were removed. Manual review of the remaining 481 study titles and abstracts yielded 23 pediatric studies, 8 case reports, 1 duplicate study, and 431 irrelevant studies, which were excluded. Of the remaining 18 studies, 7 studies lacked the required data and 1 study was found to have children in the cohort. The remaining 10 eligible studies ( 8 case-control and 2 cross-sectional), with a total of 155,032 subjects, were included in the analysis (Fig. 1). Basic characteristics of the 10 studies are described in Tables 1 and 2.

Studies were divided into 2 groups: the first group included studies that identified asthmatics and looked for the presence

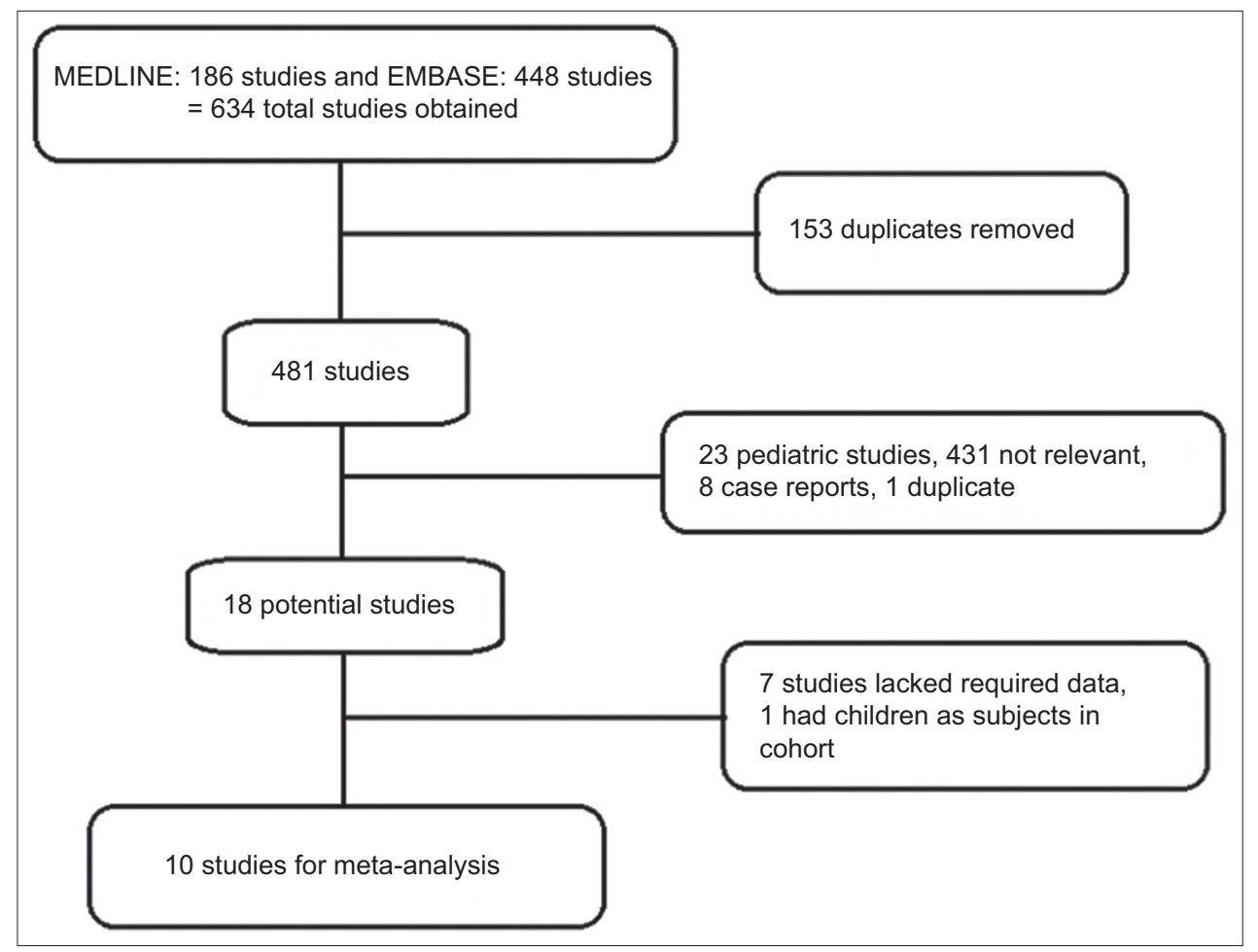

Figure 1 Literature review process 


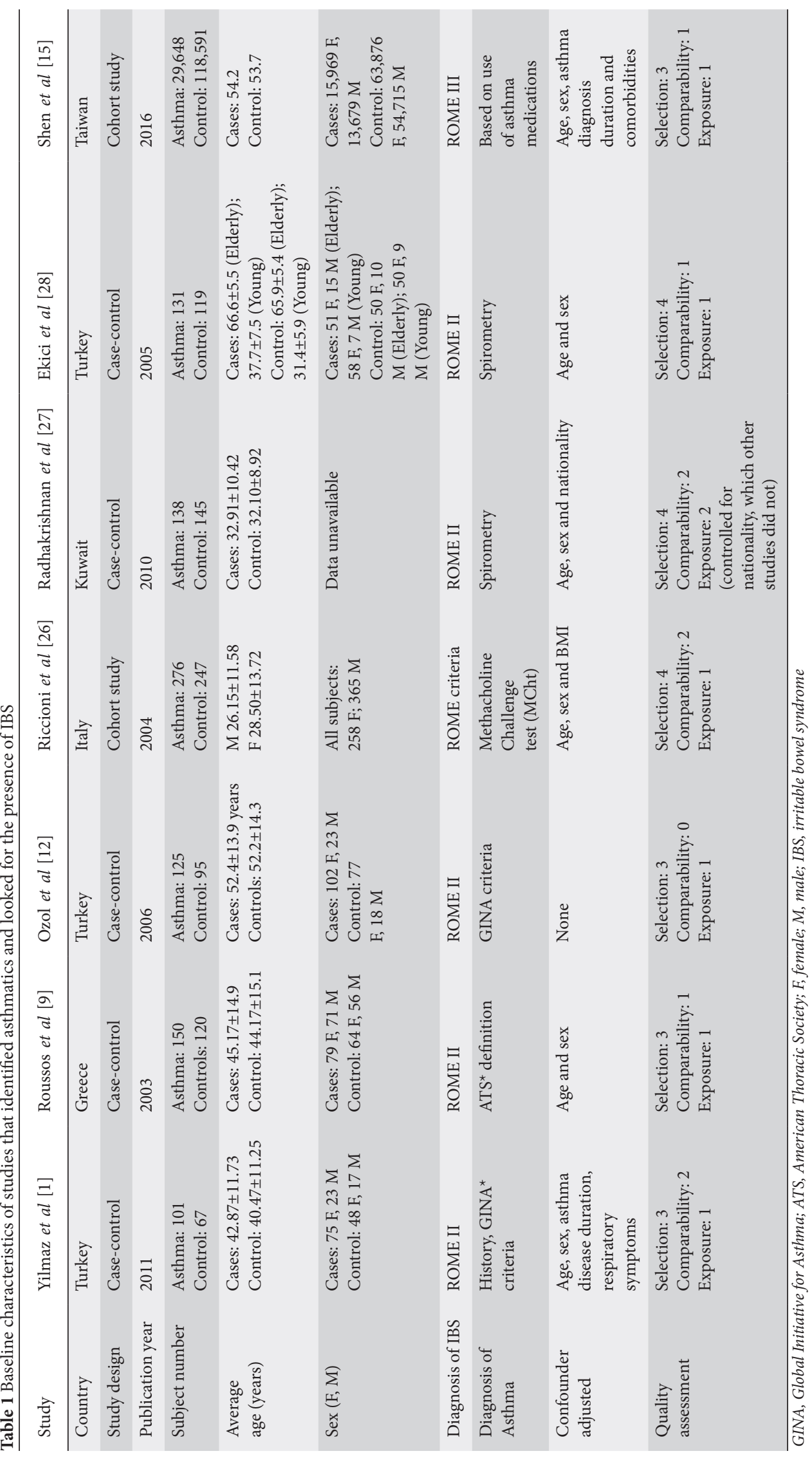


Table 2 Baseline characteristics of studies that identified patients with IBS and looked for the presence of asthma

\begin{tabular}{|c|c|c|c|c|}
\hline Study & Babak et al [29] & Yazar et al [30] & Siddiqui et al [5] & Shen et al [15] \\
\hline Country & Iran & Turkey & India & Taiwan \\
\hline Study design & Cross-sectional & Case-control & Cross-sectional study & Case-control \\
\hline Publication year & 2005 & 2001 & 2017 & 2016 \\
\hline Subject number & $\begin{array}{l}\text { IBS: } 337 \\
\text { Controls: } 4400\end{array}$ & $\begin{array}{l}\text { IBS: } 133 \\
\text { Control: } 137\end{array}$ & $\begin{array}{l}\text { IBS: } 70 \\
\text { Control: } 70\end{array}$ & $\begin{array}{l}\text { IBS: } 29,875 \\
\text { Control: } 119,500\end{array}$ \\
\hline Average age (years) & $\begin{array}{l}\text { All subjects: } \\
37.9 \pm 14.35\end{array}$ & $\begin{array}{l}\text { IBS: } 41.64 \pm 9.45 \\
\text { Control: } 39.94 \pm 10.62\end{array}$ & $\begin{array}{l}\text { IBS: } 32.91 \pm 10.42 \\
\text { Control: } 32.10 \pm 8.92\end{array}$ & $\begin{array}{l}\text { Cases: } 50.4 \\
\text { Control: } 49.9\end{array}$ \\
\hline $\operatorname{Sex}(F, M)$ & 2659 F, $2103 \mathrm{M}$ & $\begin{array}{l}\text { Cases: } 108 \text { F, } 25 \mathrm{M} \\
\text { Control: } 105 \text { F, } 32 \mathrm{M}\end{array}$ & $\begin{array}{l}\text { F: } 16 \\
\text { M: } 54\end{array}$ & $\begin{array}{l}\text { Cases: } 15,786 \mathrm{~F} ; 14,089 \mathrm{M} \\
\text { Control: } 63,144 \mathrm{~F} ; 56,356 \mathrm{M}\end{array}$ \\
\hline Diagnosis of IBS & ROME II & ROME criteria & ROME III & ROME III \\
\hline Diagnosis of Asthma & $\begin{array}{l}\text { History, Spirometry } \\
\text { results }\end{array}$ & History and spirometry & Spirometry & $\begin{array}{l}\text { Based on use of asthma } \\
\text { medications }\end{array}$ \\
\hline Confounder adjusted & Age and sex & Age, smoking status & Age and sex & $\begin{array}{l}\text { Age, sex, asthma diagnosis } \\
\text { duration and comorbidities }\end{array}$ \\
\hline Quality assessment & $\begin{array}{l}\text { Selection: } 4 \\
\text { Comparability: } 1 \\
\text { Exposure: } 1\end{array}$ & $\begin{array}{l}\text { Selection: } 3 \\
\text { Comparability: } 1 \\
\text { Exposure: } 2\end{array}$ & $\begin{array}{l}\text { Selection: } 4 \\
\text { Comparability: } 1 \\
\text { Exposure: } 1\end{array}$ & $\begin{array}{l}\text { Selection: } 3 \\
\text { Comparability: } 1 \\
\text { Exposure: } 1\end{array}$ \\
\hline
\end{tabular}

F, female; $M$, male; IBS, irritable bowel syndrome

of IBS; the second included studies that identified IBS patients and looked for the presence of asthma. Shen et al conducted a bidirectional study, therefore included in both groups [15]. The first group included 7 studies ( 5 case-controls and 2 cohort studies) with a total of 30,569 asthmatics and 11,9484 controls. The pooled OR was 2.0 (95\% confidence interval [CI] 1.5-2.8) with an $I^{2}$ value of $69.5 \%(\mathrm{P}=0.03)$ (Table 3, Fig. 2). A sensitivity analysis including only the 5 case-control studies for the meta-analysis showed an $I^{2}$ value of $0 \%(\mathrm{P}=0.8)$ and an OR of 2.6 (95\%CI 1.9-3.5) (Table 4, Fig. 3). The second group included 4 studies with 30,415 IBS patients and 12,4107 non-IBS patients. The pooled OR was 2.2 (95\%CI 1.3-3.9) with $I^{2} 81.3 \%$ $(\mathrm{P}=0.001)$ (Table 5, Fig. 4). A funnel plot was then constructed separately, including the respective studies for the outcome of IBS and asthma. For the meta-analysis that included 7 studies of the outcome of IBS, the coefficient of bias using the Harbord test was $-0.2(\mathrm{P}=0.78)$, indicating the absence of small-study effects (Fig. 5).

\section{Discussion}

IBS manifests with many debilitating symptoms, including abdominal pain, bloating, muscle pain and headache, and diagnosing it can be very challenging, considering the variability and fluctuation of disease symptoms over time and the overlap of symptoms with other conditions, such as lactose intolerance $[2-4,15]$. IBS was for a long time described by symptoms of "alternating constipation and diarrhea", but the Rome criteria introduced in the 1980s represented an attempt to better diagnose the condition. The criteria have been revised and improved over time to better classify IBS. The Rome II criteria diagnosed IBS on the basis of the presence of
Table 3 Case-control and cross-sectional studies looking at the presence/outcome of irritable bowel syndrome in asthmatics

\begin{tabular}{lcc}
\hline Study & Odds ratio & 95\% Confidence interval \\
\hline Yilmaz et al [1] & 2.65 & $1.259-5.577$ \\
Roussos et al [9] & 2.677 & $1.549-4.629$ \\
Ozol et al [12] & 3.211 & $1.537-6.706$ \\
\hline Riccioni et al [26] & 0.747 & $0.449-1.241$ \\
\hline Radhakrishna et al [27] & 2.942 & $1.706-5.074$ \\
Ekici et al [28] & 1.876 & $1.014-3.469$ \\
\hline Shen et al [15] & 1.913 & $1.802-2.03$ \\
\hline Pooled odds ratio & 2.017 & $1.469-2.769$ \\
\hline
\end{tabular}

Table 4 Case-control studies looking for the presence of irritable bowel syndrome in asthmatics

\begin{tabular}{lcc}
\hline Study & Odds ratio & 95\% Confidence interval \\
\hline Yilmaz et al [1] & 2.65 & $1.259-5.577$ \\
Roussos et al [9] & 2.677 & $1.549-4.629$ \\
Ozol et al [12] & 3.211 & $1.537-6.706$ \\
Radhakrishna et al [27] & 2.942 & $1.706-5.074$ \\
Ekici et al [28] & 1.876 & $1.014-3.469$ \\
Pooled odds ratio & 2.615 & $1.981-3.451$ \\
\hline
\end{tabular}

symptoms for at least 12 weeks; however, it did not provide any information about the subtypes of IBS [4]. The Rome III criteria subclassified IBS into primarily constipation, diarrhea, mixed, or unclassified, based on the stool consistency (using the Bristol stool form scale) [4]. Further revision led to the 


\begin{tabular}{|c|c|c|}
\hline Name & OR $(95 \% \mathrm{Cl})$ & Weight \\
\hline Yilmaz et al [1] & $2.65(1.26,5.58)$ & 10.33 \\
\hline Roussos et al [9] & $2.68(1.55,4.63)$ & 13.98 \\
\hline Ozol et al [12] & $\rightarrow 3.21(1.54,6.71)$ & 10.45 \\
\hline Riccioni et al [26] & $0.75(0.45,1.24)$ & 14.84 \\
\hline Radhakrishna et al [27] & $2.94(1.71,5.07)$ & 14.03 \\
\hline Ekici et al [28] & $1.88(1.01,3.47)$ & 12.60 \\
\hline Shen et al [15] & $1.91(1.80,2.03)$ & 23.77 \\
\hline Overall $\left(I^{2}=69.5 \%, \mathrm{P}=0.003\right)$ & $2.02(1.47,2.77)$ & 100.00 \\
\hline NOTE: Weights are from random effects analysis & & \\
\hline 0.149 & 6.71 & \\
\hline
\end{tabular}

Figure 2 Forest plot of the meta-analysis that evaluated the presence of irritable bowel syndrome in asthmatic patients. OR, odds ratio; CI, confidence interval

\begin{tabular}{|c|c|c|}
\hline Name & OR $(95 \% \mathrm{Cl})$ & Weight \\
\hline Yilmaz et al [1] & $2.65(1.26,5.58)$ & 13.89 \\
\hline Roussos et al [9] & $2.68(1.55,4.63)$ & 25.67 \\
\hline Ozol et al [12] & $\rightarrow 3.21(1.54,6.71)$ & 14.18 \\
\hline Radhakrishna et al [27] & $2.94(1.71,5.07)$ & 25.91 \\
\hline Ekici et al [28] & $1.88(1.01,3.47)$ & 20.35 \\
\hline Overall $\left(I^{2}=0.0 \%, P=0.807\right)$ & $2.61(1.98,3.45)$ & 100.00 \\
\hline $\begin{array}{l}\text { NOTE: } \\
\text { Weights are from random effects analysis }\end{array}$ & & \\
\hline 0.149 & 6.71 & \\
\hline
\end{tabular}

Figure 3 Forest plot of the meta-analysis including only case-control studies that evaluated the presence of irritable bowel syndrome in asthmatic patients $O R$, odds ratio; CI, confidence interval

Table 5 Studies looking for the presence of asthma in patients with irritable bowel syndrome

\begin{tabular}{lcc}
\hline Study & Odds ratio & 95\% Confidence interval \\
\hline Babak et al [29] & 3.014 & $2.022-4.494$ \\
Yazar et al [30] & 12.656 & $2.905-55.148$ \\
Siddiqui et al [5] & 0.828 & $0.352-1.944$ \\
Shen et al [15] & 1.811 & $1.7-1.929$ \\
Pooled odds ratio & 2.229 & $1.274-3.899$ \\
\hline
\end{tabular}

Rome IV criteria, according to which symptoms should be present during the last 3 months and for at least 6 months before the diagnosis of IBS [4].

IBS is also frequently associated with other complicated rheumatologic conditions, such as fibromyalgia and chronic pain disorders [8]. A prospective study conducted in Taiwan identified 33,729 patients (mean age 51 years) with fibromyalgia and 134,915 patients (mean age 51.5 years) without fibromyalgia using the national health insurance database. The study reported a 1.91 to 3.19-fold greater incidence of IBS 


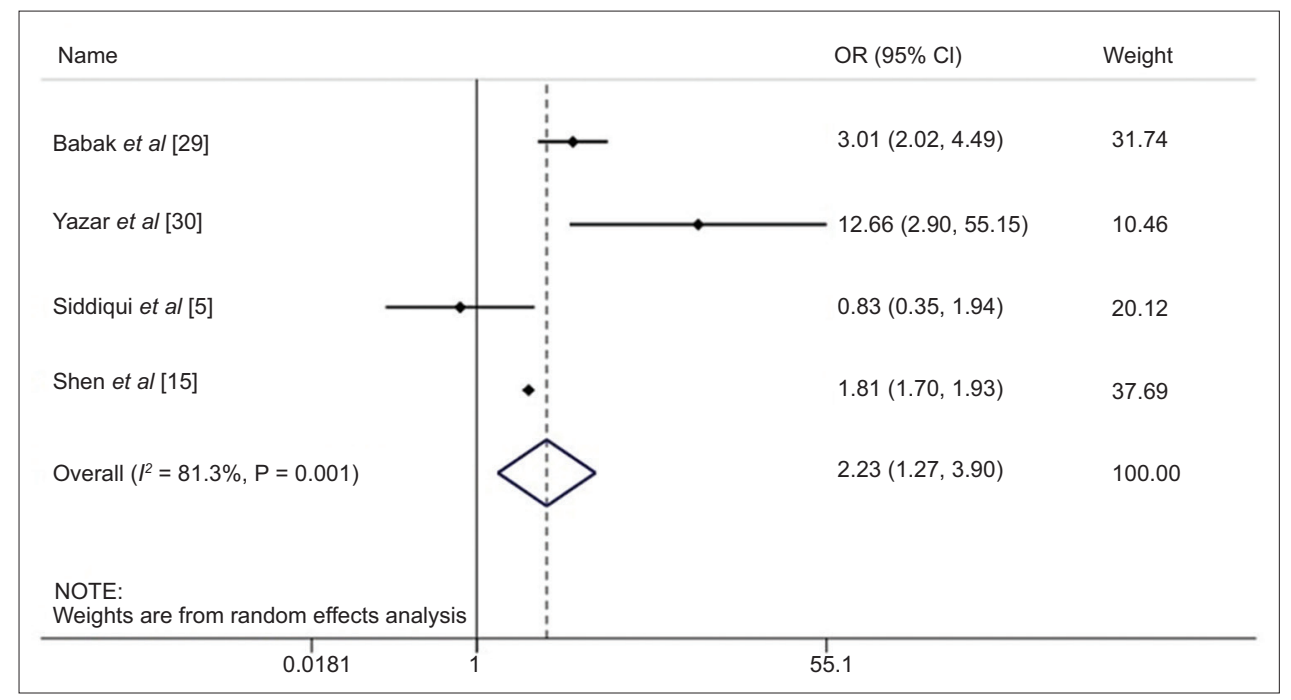

Figure 4 Forest plot of the meta-analysis that evaluated the presence of asthma in irritable bowel syndrome patients. $O R$, odds ratio; CI, confidence interval

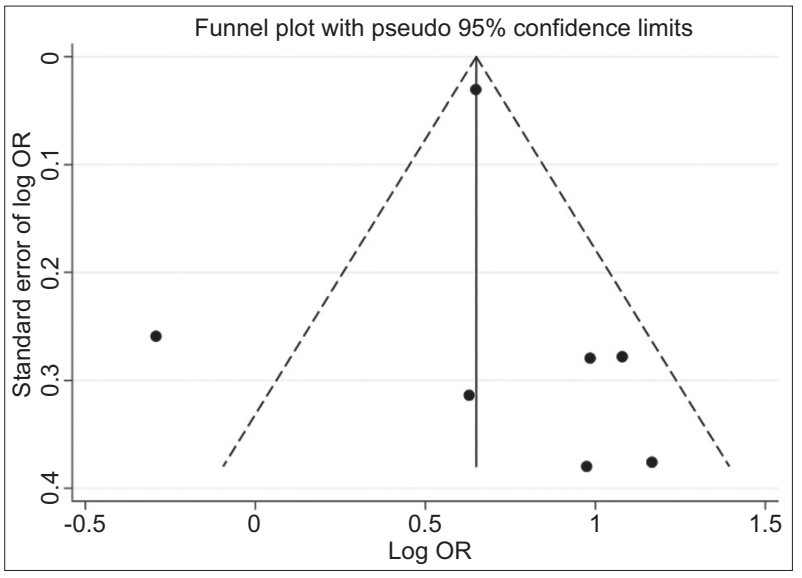

Figure 5 Funnel plot of the studies that evaluated the presence of irritable bowel syndrome in asthmatic patients

OR, odds ratio

in patients with fibromyalgia [16]. Researchers have recently been turning their attention towards understanding the association of IBS with respiratory pathologies. A recent casecontrol study with 197 patients (100 with sleep apnea and 97 without sleep apnea) conducted at a sleep laboratory in Iran looked at the association of IBS and sleep apnea. The average age of participants was $42.24 \pm 12.05$ years $(55.4 \%$ male). Of the patients who had a positive sleep apnea test, $27.1 \%$ also met the IBS diagnostic criteria, compared to $8.2 \%$ of those who had a negative sleep apnea test. This study showed a higher prevalence of IBS in patients with sleep apnea, irrespective of its severity [17]. A case-control study conducted in Egypt recruited 133 medical students, 50 with IBS (44 female) and 83 healthy controls ( 50 female), and showed that IBS patients are at a significantly higher risk of developing chronic rhinosinusitis than non-IBS patients [18].

In our study, the analysis of most studies from across the world showed a strong association between IBS and asthma. Some studies have also shown that IBS is more prevalent in asthma patients with comorbidities compared to non-asthmatics [15]. Mast cells release histamine, proinflammatory cytokines and other mediators known to cause hyperresponsiveness in atopic diseases such as asthma. They have also been shown to affect enteric nerve and smooth muscle function [19]. Omalizumab, a monoclonal antibody used for the management of asthma, also improves allergic GI symptoms [20]. Interestingly, another mechanism proposed for the association of asthma and GI symptoms is the increase in intestinal permeability, or "leaky gut syndrome" [21,22]. Hijazi et al reported that children with asthma have increased intestinal permeability compared to non-asthmatics [21]. A study in France analyzed intestinal permeability in 37 asthmatic adults (mean age $44 \pm 16$ years) and compared it to results obtained from 13 non-asthmatics with chronic obstructive pulmonary disease (COPD; mean age: $59 \pm 1.6$ years) and 26 healthy controls (mean age: $43 \pm 2$ years) [23]. Measurement of urinary chromium 51-labeled ethylenediaminetetraacetic acid (CrEDTA) was used to study intestinal permeability. The study reports that asthmatics had a significantly higher urinary CrEDTA $(2.5 \pm 1.95 \%)$ compared to the COPD and control groups $(1.16 \pm 0.48 \% ; \mathrm{P}=0.01$ and $1.36 \pm 0.14 \%$; $\mathrm{P}=0.006$, respectively) [23]. Although atopy and immune system activation to some extent has been shown to be the pathophysiological mechanism for the association of asthma with functional GI disorders, the overall pathophysiological mechanism is unknown, thus adding another level of complexity to the management of the disorder $[15,24]$ This study has some limitations that should be noted. Some of the potential studies could not be included in the analysis as they were not published studies or were case reports. Secondly, the majority of the studies did not discuss sub-classifications of IBS or the severity of asthma, and although most studies reported that spirometry was performed to confirm the diagnosis of asthma, the results were not discussed in detail. Lastly, the lack of heterogeneity, with statistically significant $I^{2}$ of $69.5 \%$ and 
$81.3 \%$ for the 2 groups of meta-analysis, is another limitation of this study.

In conclusion, there has been limited research into the association of IBS with asthma [25]. This analysis looked closely at the current evidence and noted that there is strong association between the 2 conditions. Physicians should keep a high index of suspicion for asthma in patients who present with pulmonary symptoms along with GI symptoms such as abdominal pain or discomfort, change in bowel habits and bloating [25]. On the same note, IBS patients should be informed about the possible risk of developing asthma or pulmonary symptoms. Some of the interventions that may be included in the management of these patients may include evaluation with spirometry, skin testing with food antigens, or dietary consultation.

\section{Acknowledgment}

The authors would like to acknowledge Dr. Elaine Barfield (Division of Pediatric Gastroenterology and Nutrition, New York-Presbyterian/Weill Cornell Medicine) for providing guidance and helpful comments in editing the manuscript.

\section{References}

1. Yilmaz A, Cumurcu BE, Tasliyurt T, Sahan AG, Ustun Y, Etikan I. Role of psychiatric disorders and irritable bowel syndrome in asthma patients. Clinics (Sao Paulo) 2011;66:591-597.

2. Saha L. Irritable bowel syndrome: pathogenesis, diagnosis, treatment, and evidence-based medicine. World J Gastroenterol 2014;20:6759-6773.

3. Soares RL. Irritable bowel syndrome: a clinical review. World $J$ Gastroenterol 2014;20:12144-12160.

4. Lacy BE, Patel NK. Rome criteria and a diagnostic approach to irritable bowel syndrome. J Clin Med 2017;6.

5. Siddiqui S, Misra SP, Dwivedi M, Pant S. Irritable bowel syndrome and bronchial asthma: Are they associated in Indian population. J Clin Diagn Res 2017;11:OC21-OC23.

6. Kozma CM, Barghout V, Slaton T, Frech F, Reeder CE. A comparison of office-based physician visits for irritable bowel syndrome and for migraine and asthma. Manag Care Interface 2002;15:40-43, 49.

7. Frank L, Kleinman L, Rentz A, Ciesla G, Kim JJ, Zacker C. Healthrelated quality of life associated with irritable bowel syndrome: comparison with other chronic diseases. Clin Ther 2002;24:675-689.

8. Whitehead WE, Palsson O, Jones KR. Systematic review of the comorbidity of irritable bowel syndrome with other disorders: what are the causes and implications? Gastroenterology 2002;122:1140-1156.

9. Roussos A, Koursarakos P, Patsopoulos D, Gerogianni I, Philippou N. Increased prevalence of irritable bowel syndrome in patients with bronchial asthma. Respir Med 2003;97:75-79.

10. Hossny E, Caraballo L, Casale T, El-Gamal Y, Rosenwasser L. Severe asthma and quality of life. World Allergy Organ J 2017;10:28.

11. Philpott H, Kweh B, Thien F. Eosinophilic esophagitis: current understanding and evolving concepts. Asia Pac Allergy 2017;7:3-9.

12. Ozol D, Uz E, Bozalan R, Türkay C, Yildirim Z. Relationship between asthma and irritable bowel syndrome: role of food allergy. J Asthma 2006;43:773-775.

\section{Summary Box}

\section{What is already known:}

- Irritable bowel syndrome (IBS) is very common in patients of all ages

- Both IBS and asthma affect quality of life and have a significant healthcare cost burden

\section{What the new finding is:}

- The risk of asthma in patients with IBS is twice the risk in non-IBS patients

13. Nybacka S, Öhman L, Störsrud S, et al. Neither self-reported atopy nor IgE-mediated allergy are linked to gastrointestinal symptoms in patients with irritable bowel syndrome. Neurogastroenterol Motil 2018;10:e13379.

14. Virchow JC. Eosinophilic esophagitis: asthma of the esophagus? Dig Dis 2014;32:54-60.

15. Shen TC, Lin CL, Wei CC et al. Bidirectional association between asthma and irritable bowel syndrome: two population-based retrospective cohort studies. PLoS One 2016;11:e0153911.

16. Yang TY, Chen CS, Lin CL, Lin WM, Kuo CN, Kao CH. Risk for irritable bowel syndrome in fibromyalgia patients: a national database study. Medicine (Baltimore) 2017;96:e6657.

17. Ghiasi F, Amra B, Sebghatollahi V, Azimian F. Association of irritable bowel syndrome and sleep apnea in patients referred to sleep laboratory. J Res Med Sci 2017;22:72.

18. Darweesh M. Relationship between irritable bowel syndrome and chronic rhinosinusitis: a case control study. Gut 2015;64:A317-A318.

19. Pearson JS, Niven RM, Meng J, Atarodi S, Whorwell PJ. Immunoglobulin $\mathrm{E}$ in irritable bowel syndrome: another target for treatment? A case report and literature review. Therap Adv Gastroenterol 2015;8:270-277.

20. Magen E, Chikovani T. Possible therapeutic role of IgE blockade in irritable bowel syndrome. World J Gastroenterol 2016;22:9451-9456.

21. Hijazi Z, Molla AM, Al-Habashi H, Muawad WM, Molla AM, Sharma PN. Intestinal permeability is increased in bronchial asthma. Arch Dis Child 2004;89:227-229.

22. Farshchi MK, Azad FJ, Salari R, Mirsadraee M, Anushiravani M. A viewpoint on the leaky gut syndrome to treat allergic asthma: a novel opinion. J Evid Based Complementary Altern Med 2017;22:378-380.

23. Benard A, Desreumeaux P, Huglo D, Hoorelbeke A, Tonnel AB, Wallaert B. Increased intestinal permeability in bronchial asthma. J Allergy Clin Immunol 1996;97:1173-1178.

24. Bellini M, Gambaccini D, Stasi C, Urbano MT, Marchi S, UsaiSatta P. Irritable bowel syndrome: a disease still searching for pathogenesis, diagnosis and therapy. World $J$ Gastroenterol 2014;20:8807-8820.

25. Panicker R, Arifhodzic N, Al Ahmad M, Ali SA. Association and symptom characteristics of irritable bowel syndrome among bronchial asthma patients in Kuwait. Ann Thorac Med 2010;5:37-42.

26. Riccioni G, Della Vecchia R, Menna V, Staniscia T, Di Ilio C, Conti P, D’Orazio N. Irritable bowel syndrome and bronchial hyperresponsiveness: is there a link? Digestion 2004;69:185-189.

27. Panicker R, Arifhodzic N, Al Ahmad M, Ali SA. Association and symptom characteristics of irritable bowel syndrome 
among bronchial asthma patients in Kuwait. Ann Thorac Med 2010;5:37-42.

28. Ekici A, Guiliter S, Ekci M, Kalpaklioglu F, Kara T, Keles H, Tunckol M, Akin A, Kocyigit P. Irritable bowel syndrome in young and elderly patients with stable asthma. Dig Liver Dis. 2005;37:773-778.

29. Amra B, Hoseini-Asl MK, Rahmani AR, Golshan M, Mohamad-
Zadeh Z. Correlation between asthma and irritable bowel syndrome in a general population in Iran in 2003. Respir Med 2006;100:110-114.

30. Yazar A, Atis S, Konca K, Pata C, Akbay E, Calikoglu M, Hafta A. Respiratory symptoms and pulmonary functional changes in patients with irritable bowel syndrome. Am J Gastroenterol 2001;96:1511-1516. 